\title{
Construção do conhecimento pedagógico de conteúdo na formação de licenciandos em Física
}

\author{
Angelisa Benetti Clebsch ${ }^{1}$, e José de Pinho Alves Filho² \\ angelisa.clebsch@ifc.edu.br, jopinhofilho@gmail.com \\ ${ }^{1}$ Instituto Federal Catarinense, 89160-270, Rio do Sul, Santa Catarina, Brasil \\ ${ }^{2}$ Universidade Federal de Santa Catarina, Programa de Pós-Graduação em Educação Científica e \\ Tecnológica, 88040-900, Florianópolis, Santa Catarina, Brasil
}

DOI: 10.17013/risti.28.86-101

\begin{abstract}
Resumo: Com o propósito de compreender a relação teoria-prática na construção dos saberes docentes, realizou-se um estudo que envolveu os cursos de Licenciatura em Física ofertados por instituições públicas catarinenses (Brasil). Apresentam-se as dimensões (curricular, pedagógica e prática) e categorias de análise da pesquisa. Com foco na dimensão pedagógica, este artigo apresenta como os instrumentos (questionários e entrevistas) foram elaborados e como foi realizada a coleta, organização e tratamento dos dados. Com o cruzamento dos dados e apoio do software webQDA foi possível identificar os temas que são tratados nas disciplinas Pedagógicas de Física e sua relação com a construção do Conhecimento Pedagógico de Conteúdo dos licenciandos.
\end{abstract}

Palavras-chave: Licenciatura em Física; Construção dos Saberes Docentes; Conhecimento Pedagógico de Conteúdo.

\section{Construction of the pedagogical knowledge of contents in the training of physicist graduates}

\begin{abstract}
With the purpose of understanding the theory-practice relationship in the construction of the teaching knowledge, a study was carried out that involved the undergraduate courses in Physics offered by public institutions in Santa Catarina (Brazil). The dimensions (curricular, pedagogical and practical) and categories of research analysis are presented. Focusing on the pedagogical dimension, this article presents how the instruments (questionnaires and interviews) were elaborated and how data collection, organization and processing were performed. With the data crossing and support of the webQDA software it was possible to identify the subjects that are treated in the Pedagogical disciplines of Physics and its relation with the construction of the Pedagogical Content Knowledge of the graduation students.
\end{abstract}

Keywords: Degree in Physics; Construction of Teaching Knowledge; Pedagogical Knowledge of Content. 


\section{Introdução}

As licenciaturas devem propiciar a construção dos diversos saberes necessários à profissão docente. No Brasil as diretrizes curriculares nacionais (Resolução n. 1, 2002, Resolução n. 2, 2002, Resolução n. 2, 2015) determinam a organização curricular dos cursos. Na Resolução n. 2 (2002), houve uma ampliação da carga horária prática, ficando definida em 400 (quatrocentas) horas de Estágio Curricular Supervisionado (ECS) a partir do início da segunda metade do curso e 400 (quatrocentas) horas de Prática como Componente Curricular (PCC) durante toda a formação. A PCC foi incluída nas Resoluções n. 1 e n. 2 com o propósito de promover a articulação teoria-prática durante todo o percurso formativo, no sentido de superar a concentração da dimensão prática apenas no ECS.

A organização, distribuição e implementação da PCC gerou (e ainda gera) dúvidas de acordo com pesquisas acessadas (Santos \& Lisovski, 2011; Neto \& Amaral, 2013). Com a intenção de contribuir e avançar na compreensão das relações teoria-prática, desenvolveu-se um estudo cujo objeto foi a construção dos saberes docentes, especificamente no âmbito da Licenciatura em Física. A investigação foi centrada nos componentes teóricos e práticos dos currículos das Licenciaturas. As práticas são entendidas como as atividades relacionadas à docência em Física, realizadas pelos licenciandos nas atividades de PCC e ECS.

Assim, foi proposto o seguinte problema: de que forma, nos cursos de Licenciatura em Física, os conhecimentos teórico-pedagógicos se relacionam na construção dos saberes necessários à docência? Para seu estudo, realizado por meio da Análise de Conteúdo (Bardin, 2011), foram definidas dimensões, categorias e subcategorias de análise com base em elementos obrigatórios às licenciaturas brasileiras e em teorias envolvendo saberes docentes.

O estudo focou nas práticas (ECS e PCC) e nas disciplinas Pedagógicas de Física. Estas disciplinas (por exemplo: Prática de Ensino, Metodologia do Ensino de Física, Instrumentação para o ensino de Física) ocupam-se de discussões envolvendo os conteúdos objetos de ensino na Educação Básica e, por este motivo, articulam teoria e prática.

O contexto da pesquisa foram os cursos de Licenciatura em Física, ofertados pelas instituições públicas brasileiras de ensino superior no estado de Santa Catarina (SC). O Instituto Federal Catarinense (IFC): em seus campus nas cidades de Concórdia e Rio do Sul. O Instituto Federal de Santa Catarina nos campus das cidades de Araranguá e Jaraguá do Sul. A Universidade do Estado de Santa Catarina (UDESC) na cidade de Joinville e a Universidade Federal de Santa Catarina (UFSC) na cidade de Florianópolis.

Neste artigo será apresentado o delineamento da investigação e os resultados obtidos na análise das disciplinas Pedagógicas de Física. A pesquisa completa pode ser acessada em Clebsch (2018). 


\section{A construção dos saberes docentes do Licenciando em Física}

Desde a década de 1970 vários autores têm caracterizado o conhecimento docente em direção à profissionalização ${ }^{1}$ do ensino. Entre eles temos Shulman (1986; 1987), Carvalho e Gil-Pérez (2011; 2014), Porlán Ariza e Rivero García (1998), Altet (2001) e Park e Oliver (2008).

Shulman (1986) supõe que o conhecimento docente é composto por três categorias: conhecimento do conteúdo da matéria, conhecimento pedagógico de conteúdo e conhecimento curricular. Para ele o conhecimento da matéria envolve a compreensão pelo professor dos conteúdos e da estrutura dos diferentes assuntos de uma disciplina, a ponto de poder ensinar a outras pessoas. O conhecimento pedagógico de conteúdo - PCK (abreviatura do termo Pedagogical Content Knowledge) é definido como o conhecimento do assunto para o seu ensino. Vai além do conhecimento da disciplina por si mesma e representa a intersecção entre o conhecimento de conteúdo que ele possui e os conhecimentos pedagógicos. O conhecimento curricular envolve o conhecimento dos programas e materiais instrucionais pertinentes e disponíveis à instrução de um assunto em um nível de ensino. Para Shulman (1987), o conhecimento do conteúdo é fundamental, mas não suficiente. Também são necessários os conhecimentos pedagógicos gerais, do currículo, pedagógico de conteúdo, dos alunos, do contexto educativo, fundamentos históricos e filosóficos da Educação. $\mathrm{O}$ autor considera que o conhecimento docente não é definitivo. Ele evolui e vai se modificando com contribuições das experiências concretas vivenciadas.

Park e Oliver (2008) defendem que o PCK é um conhecimento novo que integra o conhecimento docurrículo, docontextoepedagógico.Assim definem cincocomponentes do PCK para o Ensino de Ciências: orientações para o ensino, conhecimento sobre a compreensão dos alunos, conhecimento do currículo, conhecimento das estratégias instrucionais para o ensino, conhecimento da avaliação da aprendizagem e eficácia do professor.

Carvalho e Gil-Perez (2011) se dedicaram a escrever sobre as necessidades formativas dos professores de Ciências. O texto original foi publicado como parte do Projecto sobre Enseñanza de las Ciencias y las Matemáticas em Iberoamérica. Entre os aspectos essencias à formação, citados por estes autores está o conhecimento da matéria a ser ensinada, que se alinha com o conhecimento de conteúdo proposto por Shulman; adquirir conhecimentos teóricos sobre aprendizagem e aprendizagem de Ciências, saber preparar atividades, saber dirigir a atividade dos alunos, saber avaliar, utilizar a pesquisa e a inovação. Este último diz respeito à utilização pelos professores de resultados de pesquisa da própria área.

Em texto mais recente, Carvalho e Gil-Pérez (2014) distinguem três áreas de saberes necessários a uma sólida formação teórica: saberes conceituais e metodológicos da área; saberes integradores, relativos ao ensino da área e saberes pedagógicos. Explicam que a relação teoria-prática em cada campo de saberes acontece de modo desigual, pois cada teoria requer uma prática diferente.

\footnotetext{
${ }^{1}$ Quando o saber é específico de uma profissão, legitima o exercício da função profissional.
} 
Os saberes conceituais e metodológicos da área vão além de "saber o conteúdo". Incluem também a compreensão da natureza da Ciência, dos processos e métodos de construção dos conhecimentos, conhecimento sobre os desenvolvimentos científicos mais atuais, conhecimento das relações Ciência/Tecnologia/Sociedade e conhecimentos de outras disciplinas relacionadas a possíveis temas (Carvalho \& Gil-Pérez, 2014). Segundo estes autores, tais saberes auxiliam o professor a compreender as dificuldades dos estudantes na aprendizagem dos conteúdos científicos e contribuem com a construção de uma visão da natureza da Ciência mais dinâmica e condizente com suas características. A relação teoria e prática neste âmbito acontece nas aulas de laboratório.

Os saberes integradores definidos por Carvalho e Gil-Pérez (2014) se relacionam ao ensino dos conteúdos e englobam, por exemplo, saberes sobre o ensino e aprendizagem, conhecimentos sobre as linhas de pesquisa relacionadas ao ensino da área e conhecimentos relativos à preparação das aulas. Para Carvalho e Gil-Pérez (2014) a integração teoria- prática neste campo de saberes se dá nos Estágios Supervisionados, onde se estabelecem os vínculos entre o saber e o saber fazer. Entende-se que a integração teoria-prática se concretiza também nas discussões teóricas acerca do ensino de Ciências/Física e nas Práticas de Ensino realizadas nas PCC, especialmente nas disciplinas Pedagógicas de Física.

Os saberes pedagógicos são propostos por Carvalho e Gil-Pérez (2014) numa perspectiva ampla. Reúnem os saberes relacionados ao ensino dos conteúdos escolares provenientes da Didática Geral e da Psicologia da Aprendizagem. Engloba também questões da escola, organização e demais aspectos relacionados à profissão. Para os autores, neste domínio de saberes a relação teoria-prática pode ser potencializada na escola através, por exemplo, de atividades realizadas no ECS.

Porlán Ariza e Rivero García (1998) e Altet (2001) definem que o professor é um profissional que possui competências específicas que repousam sobre uma base de conhecimentos racionais (oriundos da ciência) e conhecimentos explicitados (advindos da prática). Altet (2001) apresenta como base do conhecimento docente, os saberes teóricos e práticos. Os saberes teóricos englobam os saberes a serem ensinados (os disciplinares e os tornados didáticos) e os saberes para ensinar (pedagógicos relativos à gestão da sala), didáticos e saberes da cultura.

Os saberes práticos, definidos como os procedentes da experiência e das situações de trabalho são distinguidos em (a) saberes procedimentais sobre a prática, relativos ao como fazer e, (b) saberes da prática, produtos da ação (Altet, 2001). Os saberes práticos são similares à experiência profissional proposta por Porlán Ariza e Rivero García (1998). Esta classificação ajuda a distinguir os saberes que envolvem a reflexão sobre a prática profissional e os que são construídos na própria atuação.

Com base nas ideias sobre saberes docentes e na legislação oficial brasileira (Resolução n. 1, 2002, Resolução n. 2, 2002) foram definidas as dimensões e categorias de análise, conforme apresenta-se a seguir.

\subsection{Dimensões e categorias de análise da pesquisa}

A Dimensão Curricular visou analisar a distribuição de saberes teóricos e práticos nos currículos dos cursos. Com base na divisão de saberes de Carvalho e Gil-Pérez (2014) e 
Altet (2001), a dimensão foi subdivida nas categorias (1) saberes de Física, (2) saberes teórico-práticos e (3) saberes práticos. A categoria saberes de Física teve como objetivo identificar as disciplinas que abordam saberes conceituais da área (Física, Matemática e disciplinas complementares) e saberes metodológicos da área (Laboratório, Tecnologias ou História e Filosofia da Ciência).

A categoria saberes teórico-práticos relativos à profissão foi subdividida em (1) saberes integradores e (2) saberes pedagógicos. A categoria foi assim chamada porque embora as disciplinas pedagógicas trabalhem conceitos teóricos, todos são relativos à profissão docente. Definiu-se saberes integradores para identificar as disciplinas Pedagógicas de Física. A categoria saberes pedagógicos serviu para identificar as disciplinas responsáveis pela construção de saberes da profissão como História da Educação Psicologia da Educação.

Com base em Altet (2001) e no currículo oficial das licenciaturas brasileiras (Resolução n. 1, 2002, Resolução n. 2, 2002) foi definida a categoria saberes práticos. Suas subcategorias: (1) da prática e (2) sobre a prática, serviram para analisar a distribuição, respectivamente, dos ECS e PCC.

A Dimensão Pedagógica focou nas disciplinas Pedagógicas de Física, que em sua gênese articulam teoria e prática. Estas disciplinas têm relação direta com o contexto da profissão, uma vez que várias temáticas tratadas nestas disciplinas são decorrentes de desenvolvimentos da área de pesquisa em Ensino de Física. Dentro desta dimensão foram definidas duas categorias.

A primeira, saberes integradores, para identificar os conhecimentos teórico-pedagógicos tratados nestas disciplinas. Para Carvalho e Gil-Pérez (2014), os conhecimentos relativos ao ensino de uma área específica são provenientes de pesquisas socializadas em Encontros e Periódicos Científicos. Assim, as subcategorias foram adaptadas das áreas temáticas do Simpósio Nacional de Ensino de Física - SNEF, realizado desde 1970 e que tem contribuído no desenvolvimento da área de Pesquisa em Ensino de Física no Brasil.

A segunda, saberes pedagógicos específicos, teve como referência o PCK de Shulman (1987). Se defende que as disciplinas Pedagógicas de Física são espaços propícios à construção do PCK e que podem integrar, de modo efetivo, os conhecimentos específicos da área e os pedagógicos. Foram utilizadas como subcategorias de análise os componentes do PCK propostos por Park e Oliver (2008) para o ensino de Ciências.

A Dimensão Prática foi definida para aprofundar aspectos relativos à realização dos ECS e PCC. Desta forma, visando identificar e analisar as Práticas de Ensino foi definida a primeira categoria de análise, articulação teoria-prática para identificar como os cursos preveem a articulação teoria-prática. A segunda categoria foi pedagógico em ação, com base no PCK, para analisar as Práticas de Ensino propostas aos licenciandos utilizando como subcategorias as etapas do Modelo de Raciocínio Pedagógico e Ação (Shulman, 1987). Argumenta-se que as Práticas de Ensino, contribuem no desenvolvimento do PCK dos licenciandos, por meio da vivência de ações pedagógicas.

Neste artigo apresenta-se como as dimensões e categorias foram utilizadas no desenvolvimento da pesquisa, com ênfase na Dimensão Pedagógica. Os resultados apresentados buscaram responder as seguintes questões de pesquisa: a) quais os 
conhecimentos teórico-pedagógicos que fazem parte dos cursos de Licenciatura em Física em Santa Catarina/Br? e b) como se estabelece a relação teoria-prática nas disciplinas Pedagógicas de Física?

\section{Metodologia}

Foram definidas três etapas para a pesquisa. Na primeira foi realizada exploração dos documentos legais e artigos publicados em periódicos, com o objetivo de identificar como se constituiu historicamente o currículo da Licenciatura em Física no Brasil. Esta pesquisa aliada aos aportes teóricos acerca dos saberes docentes, permitiu a definição das dimensões e categorias de análise para observação da Licenciatura em Física em um âmbito genérico. Na figura 1 apresentam-se as dimensões e categorias de análise da pesquisa. As categorias com letra vermelha mostram modificações realizadas no decorrer do estudo.

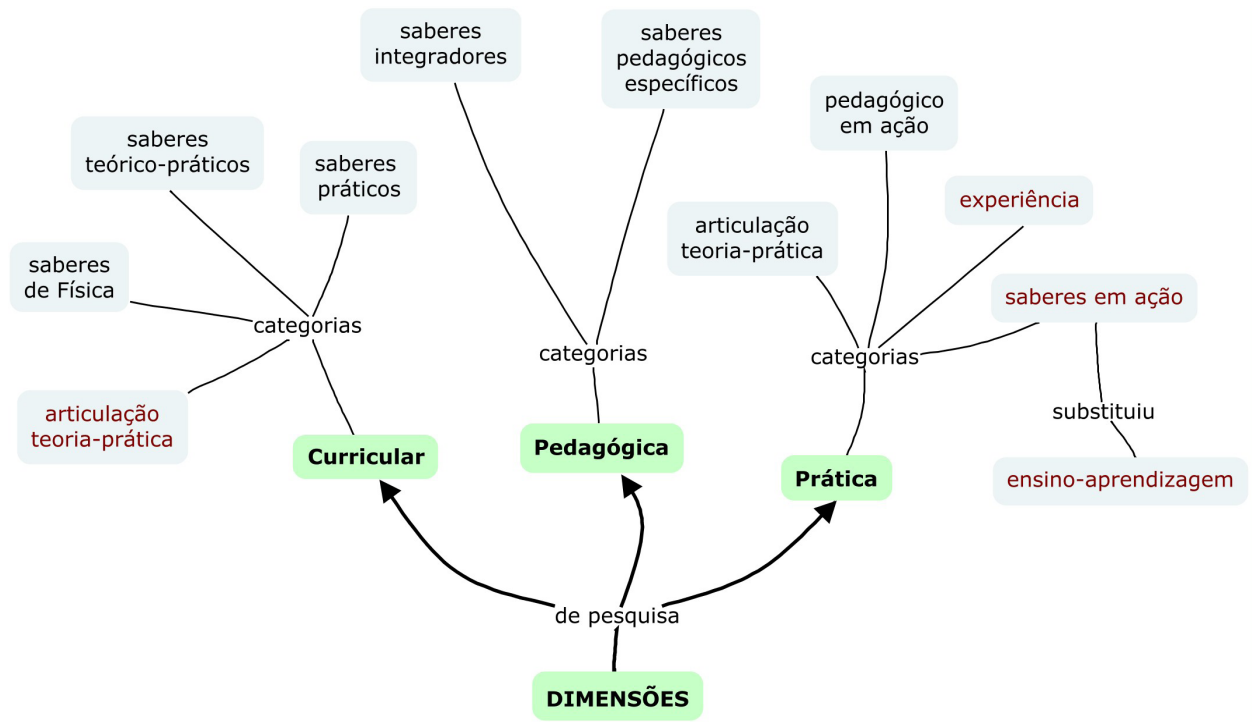

Figura 1 - Dimensões e categorias de análise

Na segunda etapa foi realizada consulta aos Projetos Pedagógicos dos Cursos das Licenciaturas em Física em SC/Br vigentes para os concluintes em 2016. Em seguida analisaram-se também os Planos de Ensino das disciplinas Pedagógicas de Física e Estágios Curriculares Supervisionados.

Na última fase foram aplicados questionários e entrevistas com dois grupos distintos de sujeitos: docentes formadores e licenciandos das seis instituições envolvidas. Nesta fase é que realizou-se ajustes nas categorias de análise. Na Dimensão Curricular, utilizou-se apenas a categoria articulação teoria-prática, já que a análise dos documentos permitiu identificar como cada curso distribuiu os componentes teóricos e práticos. A Dimensão Prática teve suas categorias ampliadas com a inclusão da categoria experiência, para analisar as atividades de PCC e ECS. A categoria ensino-aprendizagem para identificar a 
influência do ensino vivenciado pelos licenciandos como alunos, nas Práticas de Ensino por eles aplicadas nas PCC e ECS. A categoria saberes em ação emergiu dos dados das entrevistas aplicadas com os licenciandos.

\subsection{Elaboração dos instrumentos de coleta de dados}

Os questionários foram elaborados em sua maioria com questões do tipo Likert para investigar o grau de concordância/discordância, grau de importância ou, grau de avaliação atribuído às afirmativas. Nestas questões foram usados valores numéricos inteiros associados aos valores nominais, já que se empregou uma abordagem quantitativa através da média ponderada para cada uma das afirmativas. $\mathrm{O}$ resultado encontrado para cada afirmativa é conhecido como Ranking Médio (Fonseca \& Santos, 2015).

Para a Dimensão Pedagógica, foram elaboradas duas questões. Uma delas tinha por objetivo identificar a importância atribuída aos temas tratados nas disciplinas Pedagógicas de Física atribuída pelos grupos. A outra questão buscou indicativos de articulação teoria-prática nas disciplinas Pedagógicas de Física, através da presença de componentes do PCK. Além disso buscou identificar o grau de contribuição das disciplinas no desenvolvimento do PCK.

As entrevistas foram realizadas para esclarecer questões que apresentaram muitas divergências nas respostas e que geraram dúvidas em sua interpretação, bem como outras informações não obtidas por meio dos questionários. Foram elaborados dois roteiros para as entrevistas semi-estruturadas, cada um deles dirigido a um dos grupos de participantes.

Na parte alusiva à Dimensão Pedagógica, foram criadas perguntas diferentes para os grupos dentro da categoria saberes integradores. Para os formadores questionou-se sobre os temas tratados nas disciplinas para comparar com o resultado do questionário. Ainda uma questão para esclarecer por que os temas Alfabetização Científica eTecnológica e Práticas Experimentais no Ensino de Física foram considerados extremamente importantes no questionário. Para os licenciandos uma pergunta, que buscou entender porque o grupo atribuiu no questionário um grau de importância extremo para o tema Práticas Experimentais no Ensino de Física.

Dentro da categoria saberes pedagógicos específicos, buscou-se indicativos de articulação entre os conhecimentos científicos e didáticos e as Práticas de Ensino realizadas nas disciplinas Pedagógicas de Física junto aos dois grupos. Para os licenciandos foram elaboradas mais duas perguntas para esclarecer a contribuição das disciplinas na construção de dois componentes do PCK que foram avaliados nos questionários com menor grau de contribuição em relação aos outros.

\subsection{Recolha dos dados}

Os questionários foram gerados em arquivo de texto e depois transformados em formato eletrônico no SurveyMonkey (https://pt.surveymonkey.com/), uma plataforma online para criação de questionários. $\mathrm{O}$ encaminhamento aos participantes foi realizado via correio eletrônico, contendo o convite para a pesquisa, o Termo de Consentimento Livre e Esclarecido (TCLE) e o link para o questionário. O questionário 1 foi encaminhado a 44 formadores, com retorno de 23 questionários completos. O questionário 2 foi enviado a 97 licenciandos, com um retorno de 43 questionários completos. Foram realizados três envios para cada um dos grupos com um intervalo médio de 15 dias. 
Após a análise dos questionários foram realizadas 27 entrevistas presenciais, sendo 4 delas realizada para treino. Das 23 entrevistas consideradas válidas, 11 foram realizadas com formadores e 12 com licenciandos, incluindo de 1 até 3 representantes por grupo de cada uma das instituições, de acordo com a disponibilidade dos sujeitos.

\subsection{Organização e tratamento dos dados}

Encerrados os questionários, os dados foram extraídos da plataforma em arquivos digitais (formatos pdf, excel ou csv) por questão individualizada ou em um pacote único. As informações do arquivo em formato pdf com todos os dados forneceu um espelho das respostas (afirmativas, comentários e respostas abertas) individualizadas. Os dados apareceram numerados por participante, em sequência de data e hora de resposta, no anonimato, de modo que não foi possível conhecer o respondente. Para as questões do tipo Likert, a plataforma forneceu análise que incluiu a média ponderada para cada afirmativa. Os resultados foram organizados em gráficos e tabelas que foram interpretados qualitativamente. A análise dos comentários e questões abertas foi realizada manualmente.

Os arquivos de áudio das entrevistas foram transcritos para arquivos de texto, utilizando para cada entrevistado um código - (D/L-X-U/IF). A primeira letra (D ou L) identifica se o entrevistado é docente formador (D) ou licenciando (L) e o número (X) a sequência de entrevistados. A última notação identifica a instituição do arguido, sendo U relativo à Universidade e IF a Instituto Federal.

Para auxiliar na análise qualitativa dos dados das entrevistas foi utilizado o software webQDA, que permite editar, visualizar, interligar e organizar documentos (Costa, Linhares \& Souza, 2012). A escolha do WebQDA aconteceu pelo fato de o mesmo ser compatível com o sistema Linux e ainda pela vantagem de ser totalmente on line, permitindo a mobilidade e acesso aos dados de qualquer computador (Freitas, Souza, Costa \& Mendes, 2016). Além de outras vantagens mencionadas por Costa e Reis (2017). Os autores deste artigo se encaixam no perfil da maioria dos utilizadores do software, que de acordo com Freitas et al. (2016) exercem a função docente e/ou são pesquisadores.

Inicialmente, o projeto foi inserido no webQDA utilizando o sistema de códigos em árvore. Cada categoria foi considerada como nó principal e suas subcategorias como subnós. No sistema de fontes internas do webQDA foram colocados os arquivos de texto referentes à transcrição de cada entrevista. A leitura das respostas a cada questão buscou padrões e comparou os dados. Depois foram codificados os segmentos de texto de cada questão, por sujeito de pesquisa, indexando-os às subcategorias de análise criadas no software. O trabalho de Clebsch e Alves Filho (2018) exemplifica como as categorias e subcategorias de análise da dimensão pedagógica foram codificadas.

\section{Resultados e discussão}

Como resultado da Dimensão Pedagógica, dentro da categoria saberes integradores, apresenta-se a figura 2 que reúne o grau de importância atribuído aos temas tratados nas disciplinas Pedagógicas de Física nos questionários.

No eixo vertical apresentam-se as afirmativas da questão. Para cada uma delas o questionado poderia se manifestar assinalando uma das seguintes alternativas: 
não se aplica, sem importância, pouco importante, importante, muito importante e extremamente importante. Cada alternativa de resposta foi associada a um valor numérico inteiro (1 até 6), representado no eixo horizontal. O grau de importância é a média ponderada obtida para cada afirmativa.

Observa-se pela figura 2 que os formadores atribuem maior importância aos temas do que licenciandos. Alguns deles como Práticas Experimentais para o Ensino consideradas extremamente importantes pelos dois grupos foram investigados nas entrevistas. Ao analisar os resultados por subcategoria, obtivemos a maior média para pesquisa em ensino de Ciências e Física (afirmativa $i$ ) para os formadores e materiais, métodos e estratégias de ensino (afirmativas $g, h, l, o$ ) para os licenciandos. O segundo maior grau de importância atribuído pelos dois grupos foi para linguagem e Ensino de Física (afirmativas $a$ e $c$ ).

Os formadores atribuíram o mesmo grau de importância para os temas: ensinoaprendizagem em Ciências/Física (afirmativas $b, e$ ), materiais, métodos e estratégias de ensino e prática docente (afirmativas $d, j, k, p$ ). Dentre estes, os licenciandos atribuíram maior grau de importância a materiais, métodos e estratégias de ensino. Na subcategoria seleção, organização e conhecimento do currículo (afirmativas $f, m, n$ ) observa-se que os temas foram considerados mais importantes para os licenciandos do que para os formadores.

$\mathrm{Na}$ entrevista os formadores declararam as temáticas tratadas nas disciplinas de Física, o que inclui temas ligados às linhas de pesquisa da área de Ensino de Física, de acordo com as categorias de análise. Os temas mais citados pelos formadores são ligados a materiais, métodos e estratégias de ensino. Há a defesa de que devem ser trabalhadas diferentes modalidades didáticas, em geral com suporte de artigos da área, contendo pesquisas ou relatos de experiência sobre a utilização das metodologias. Foi aludido pela maioria dos formadores temas ligados a linguagem e ensino de Física.

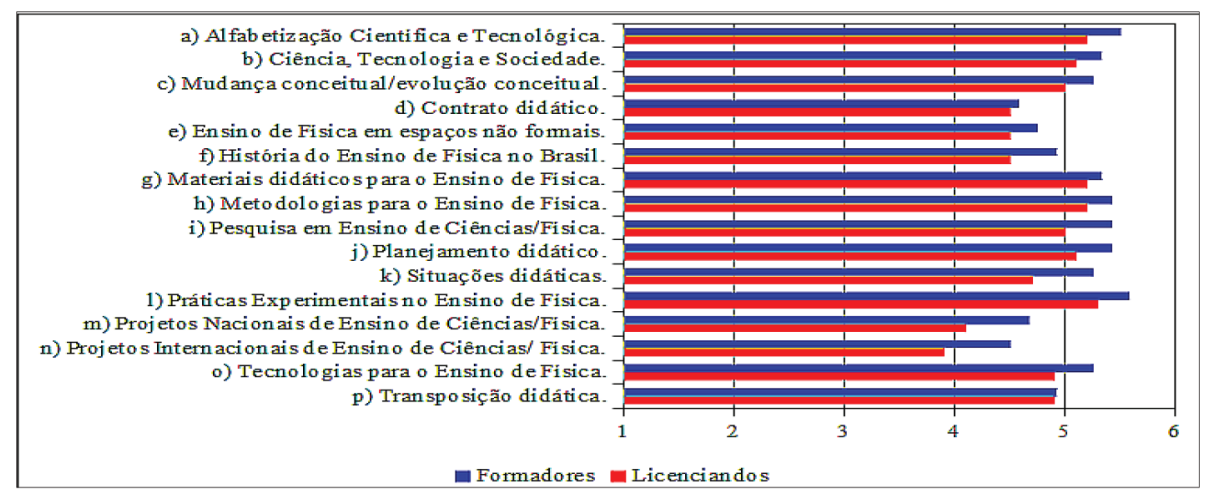

Figura 2 - Grau de importância atribuído aos temas tratados nas disciplinas

Com relação aos temas de extrema importância, alguns docentes consideram que a Alfabetização Científica e Tecnológica (ACT) é importante para que os estudantes utilizem adequadamente a linguagem científica e compreendam diversos fenômenos que acontecem no dia-a-dia. Os docentes das Universidades mencionam que trabalham ACT 
ligada a outros temas, como Ciência Tecnologia e Sociedade ou Divulgação Científica, conforme amostra seguinte: "Alfabetização Científica eu trabalho em geral junto ou com Divulgação Científica que é outro tema que trabalho, com textos de Divulgação Científica ou com CTS, ou com os dois" (D3U, 2017).

Com relação ao tema Práticas Experimentais no Ensino de Física, predominantemente os entrevistados de ambos os grupos reportam-se à finalidade das atividades experimentais, a exemplo do recorte seguinte: "Então, se eles vão é... propor um experimento de Física, eu peço para eles que tenham bem claro quais são os objetivos de demonstrar o experimento ou de pedir para que os estudantes executem o experimento" (D7IF, 2017).

É consenso entre os docentes que é importante discutir na Licenciatura as diferentes formas de utilizar experimentos. Pelos dados, há um reflexo do posicionamento destes docentes na fala dos licenciandos das diferentes instituições, a exemplo do recorte seguinte: "[...] existem vários níveis de liberdade intelectual que a gente dá para o aluno na hora que a gente tá discutindo um experimento" (L7IF, 2017). Percebeu-se que há uma compreensão por parte dos licenciandos dos diferentes tipos de abordagem experimental.

\subsection{Contribuição das disciplinas para a construção do PCK}

Na figura 3 apresenta-se o grau de avaliação que os questionados atribuíram aos temas relacionados aos componentes do PCK, como resultado da categoria saberes pedagógicos específicos. Para os licenciandos foi perguntado se admitem que as disciplinas contribuem na apreensão dos conhecimentos. Para os formadores, se admitem que os tópicos sejam tratados nas disciplinas. No eixo vertical da figura estão as afirmativas da questão, sendo a afirmativa $i$ específica para os formadores e a $j$ específica para os licenciandos. As opções de resposta foram associadas a valores numéricos: não (1), muito pouco (2) e sim (3).

a) Origem/evolução/construção das teorias científicas.

b) Fundamentos construtivistas para o ensino de Física.

c) Objetivos do ensino de Física no Ensino Médio.

d) Conteúdos de Física do Ensino Médio.

( Estratégias para o ensino de diferentes conteúdos de Física. lecursos didáticos para o ensino de Física no Ensino Médio.

g) Tratamento sobre Concepções Alternativas.

h) Avaliação da aprendizagem em Física.

i) Didática da Física.

j) Dificuldades de aprendizagem dos alunos

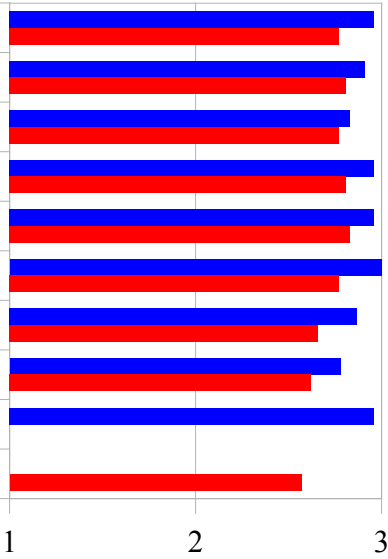

Formadores Licenciandos

Figura 3 - Tópicos relacionados aos componentes do PCK 
Observa-se nesta figura que a média obtida para cada afirmativa do grupo dos formadores é bem alta e supera a dos licenciandos. Ao analisar por subcategoria de análise, para os formadores, a concordância com o tratamento dos tópicos nas disciplinas é maior para conhecimento do currículo (afirmativas $d, f$ ). Já aos licenciandos a concordância se registra maior em conhecimento das estratégias instrucionais para o ensino (afirmativa i). Para os formadores esta subcategoria reúne as afirmativas $e$, $i$. Na subcategoria orientações para o ensino (afirmativas $a, b, c$ ) observa-se que ambos os grupos têm concordância positiva de que são tratados nas disciplinas.

Dos licenciandos obteve-se a menor média para as subcategorias conhecimento da compreensão dos alunos (afirmativas $g, h, j$ ) e conhecimento da Avaliação da aprendizagem (afirmativas $h, i$ ), por isso foram objetos de análise nas entrevistas. Os resultados obtidos na categoria são indicativos de articulação teoria-prática nas disciplinas Pedagógicas de Física, no sentido da integração entre os conhecimentos científicos e didáticos.

Pelas respostas das entrevistas a maioria dos formadores e todos os licenciandos consideram que há articulação entre as Práticas de Ensino, os conhecimentos de Física e os pedagógicos. Nas práticas elaboradas/aplicadas nas disciplinas, os formadores solicitam que o licenciando tenha domínio do conteúdo físico envolvido e justifiquem a escolha das abordagens para o seu ensino.

Foi confirmado na entrevista aos docentes, o estudo de tópicos relacionados aos componentes do PCK, quando se analisou por subcategoria. Em orientações para o ensino, foi identificado orientações para o entendimento da forma como o conhecimento físico é apresentado nos livros didáticos. Vários docentes mencionaram assuntos que auxiliam os licenciandos a se apropriarem de conhecimentos relativos ao conhecimento currículo, como análise de Projetos da área de Ensino de Física e estudo e planejamento de ações de ensino para as diferentes áreas da Física.

A maior parte dos docentes mencionou temas abordados nas disciplinas Pedagógicas de Física que podem contribuir para que os licenciandos construam conhecimentos acerca de estratégias instrucionais para o ensino, como atividades experimentais e ensino por investigação. Em conhecimento da compreensão dos alunos, de acordo com os docentes e licenciandos são inseridas nas disciplinas discussões sobre Concepções Alternativas, dificuldades de aprendizagem, interesses e motivações dos estudantes e questões envolvendo afetividade.

Com relaçãoa conhecimento daAvaliação daAprendizagem tivemos poucas manifestações de docentes. Já os licenciandos mencionaram que a Avaliação é complexa, a exemplo do extrato: "Mas esta questão do conteúdo, como vou avaliar o conteúdo. É... Fazer isso diferente do que a gente conhece como as tradicionais provas, é muito difícil." (L3U). De acordo com os licenciandos, os formadores das disciplinas defendem que sejam utilizadas várias estratégias e tipos de avaliação para avaliar a aprendizagem dos estudantes.

Para reunir os dados das entrevistas das duas categorias de análise da Dimensão Pedagógica, foram criadas matrizes quadrangulares com o uso da ferramenta questionamento do WebQDA. Observando o nome das subcategorias e palavras-chaves agregamos os dados das subcategorias que identificamos por apresentarem pontos de convergência, conforme tabela 1. 
Na tabela 1, o número de fontes são as entrevistas codificadas e o número de referências indica os trechos codificados. Estes valores trazem indícios da contribuição das disciplinas na construção dos componentes. No entanto a análise pautou-se nos trechos codificados que foram acessados em cada célula das matrizes. Através deste resultado foi possível perceber pontos de confluência entre a categoria saberes integradores, que tem como subcategorias temáticas advindas da área de Pesquisa em Ensino de Física e, componentes do PCK.

\begin{tabular}{|c|c|c|c|c|}
\hline \multirow[b]{2}{*}{ Matriz } & \multicolumn{2}{|c|}{ Subcategoria que reúne } & \multirow[b]{2}{*}{ Fontes } & \multirow[b]{2}{*}{ Referências } \\
\hline & Saberes integradores & $\begin{array}{l}\text { Saberes pedagógicos } \\
\text { específicos }\end{array}$ & & \\
\hline M1 & $\begin{array}{l}\text { Materiais, métodos e } \\
\text { estratégias de ensino }\end{array}$ & $\begin{array}{l}\text { Conhecimento das estratégias } \\
\text { instrucionais para o ensino }\end{array}$ & 22 & 57 \\
\hline M2 & $\begin{array}{l}\text { Ensino-aprendizagem em } \\
\text { Ciências/Física }\end{array}$ & $\begin{array}{l}\text { Conhecimento da } \\
\text { compreensão dos alunos }\end{array}$ & 21 & 28 \\
\hline M3 & $\begin{array}{l}\text { Seleção organização e } \\
\text { conhecimento do currículo }\end{array}$ & Conhecimento do currículo & 10 & 31 \\
\hline $\mathrm{M}_{4}$ & $\begin{array}{l}\text { Pesquisa em Ensino de } \\
\text { Ciências/Física }\end{array}$ & Orientações para o ensino & 5 & 8 \\
\hline
\end{tabular}

Tabela 1 - Matrizes quadrangulares

\section{Considerações finais}

Os resultados encontrados mostram que os conhecimentos teórico-pedagógicos tratados nas disciplinas Pedagógicas de Física são originários de pesquisas da área de Ensino de Física. Portanto corrobora com Carvalho e Gil-Pérez (2014), que afirmam que os saberes integradores são relacionados ao ensino da área. Ao mesmo tempo, os resultados estão em consonância com as ideias de Porlán Ariza e Rivero García (1998), que argumentam que as Didáticas Específicas permitem a integração de patamares de saberes.

Foram encontrados indícios de contribuição das disciplinas na construção dos componentes do PCK (Park e Oliver, 2008). Na figura 4, apresenta-se um mapa conceitual que reúne os resultados obtidos nos questionários e entrevistas para os componentes do PCK (categoria saberes pedagógicos específicos) e demonstra pontos de confluência com os saberes integradores. Tendo em vista a especificidade do PCK, o chamamos de Conhecimento Pedagógico de Física.

Observa-se pela figura 4 que as disciplinas contribuem com a construção de Orientações para o ensino através do debate sobre a origem/evolução/construção das teorias científicas. Deste modo os licenciandos podem construir uma concepção de Ciência para orientar suas decisões, além de considerar conhecimentos que têm sido construídos na área de Pesquisa em Ensino de Física e que podem ser utilizados como aportes teóricos na prática docente. Dos questionários observou-se que ocorre a discussão sobre os objetivos do ensino de Física no Ensino Médio, e que isso os orienta no planejamento do ensino. Percebemos confluência de orientações para o ensino com o tema pesquisa em Ensino de Ciências/Física. 
Os licenciandos manifestaram na entrevista que, com base na Aprendizagem Significativa, identificam os pré-requisitos para o ensino dos conteúdos além de considerar os interesses dos alunos, o que traz indícios de contribuição na construção de conhecimentos sobre dificuldades de aprendizagem dos alunos. Além disso, a motivação e a afetividade são estudadas nas disciplinas. Observa-se conformidade com o tema ensino-aprendizagem em Física, na qual foi mostrado que aspectos afeto-cognitivos e Teorias de Aprendizagem estão presentes nas disciplinas.

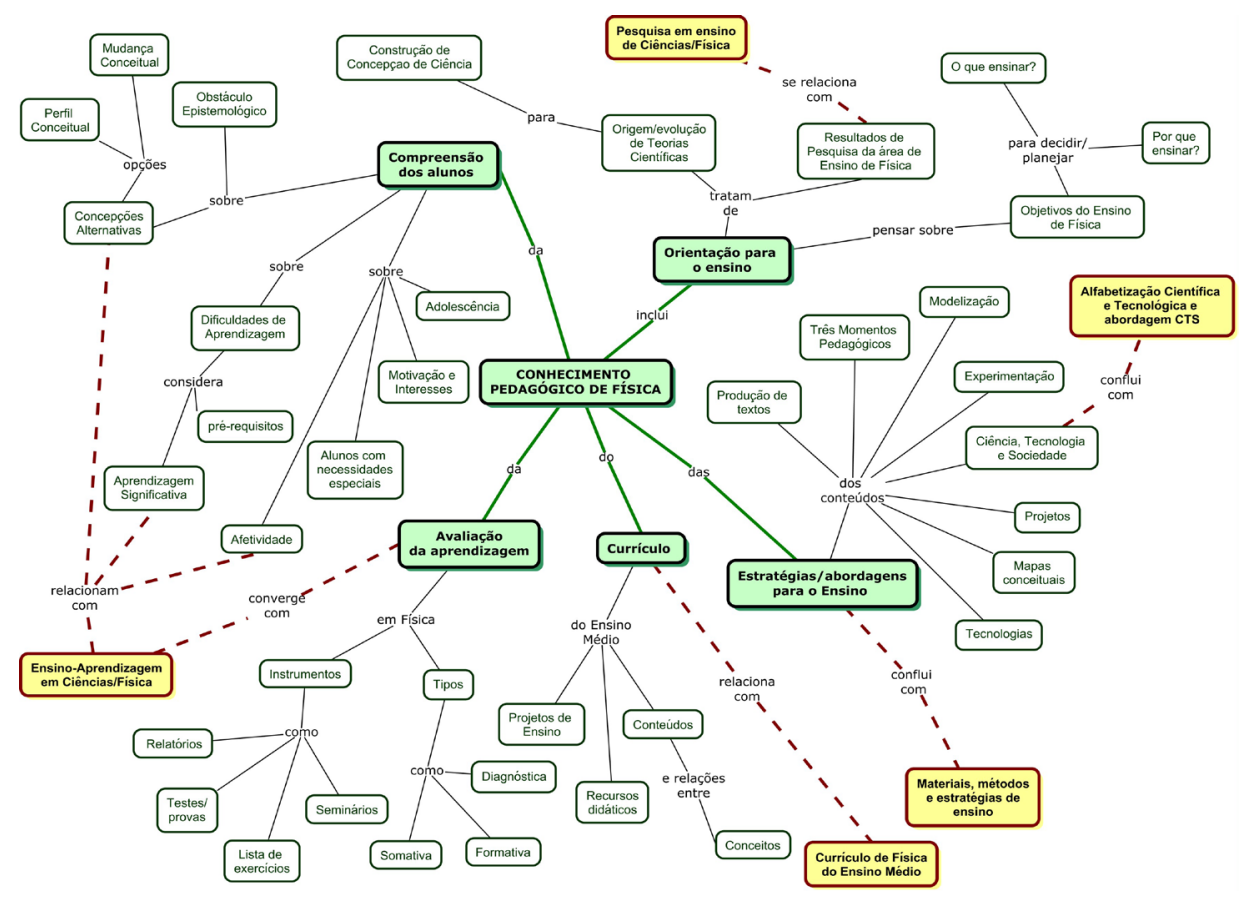

Figura 4 - Cruzamento dos dados da dimensão pedagógica

Os questionários confirmaram que as disciplinas permitem conhecer os conteúdos de Física a ser ministrado no Ensino Médio, além de recursos didáticos para o ensino, o que contribui na construção de conhecimento do currículo. Nas entrevistas os licenciandos mencionaram o estudo e elaboração de Projetos Temáticos, enquanto os formadores o estudo de relações entre os conceitos físicos e análise de projetos de ensino. Esta subcategoria congrega o que foi encontrado no tema seleção, organização e conhecimento do currículo.

Foi confirmada nos questionários a contribuição das disciplinas na construção de conhecimento das estratégias instrucionais para o ensino. O estudo de estratégias como a Experimentação e a realização do ensino por projetos foram atestados nas entrevistas. Os licenciandos ainda mencionaram que são utilizadas como estratégias a produção de textos e mapas conceituais. Os formadores indicam quetrabalham ouso de Tecnologias e Modelização, além das abordagens Ciência, Tecnologia e Sociedade e Três Momentos Pedagógicos. Estes dados confluem com o que foi demonstrado para materiais, métodos e estratégias de ensino. 
Verifica-se nos questionários que as disciplinas promovem discussões sobre Avaliação da aprendizagem em Física, contribuindo com a construção de conhecimento da Avaliação da Aprendizagem. Na entrevista os formadores mencionaram concepção e tipos de avaliação. Já os licenciandos defendem o uso de vários instrumentos de avaliação.

Pelos resultados é possível inferir que a articulação teoria-prática nas disciplinas Pedagógicas de Física é forte e ocorre através de suas temáticas, oriundas de pesquisas da área de Ensino de Física, que trazem aportes teóricos para a construção do PCK. Como as questões de pesquisa são genéricas, não foi tratado um tópico específico como nos trabalhos de Montenegro e Fernandez (2015) e Melo, Cañada e Díaz (2017).

Mostra-se o PCK profissional para o ensino de Física, por isso foi chamado Conhecimento Pedagógico de Física. Enquanto o conhecimento do conteúdo/saberes da área é comum a vários profissionais de uma mesma área e o conhecimento/saber pedagógico é genérico (comum à docência), o conhecimento pedagógico de conteúdo (PCK) é específico da docência em uma área.

O estudo aqui apresentado corrobora as ideias apresentadas por Melo et al. (2017) que defendem a inclusão do PCK como um quadro teórico para a formação de professores, tendo vista a exigência atual de entender o que significa ensinar e aprender Física. Para eles a inclusão do PCK mostra a necessidade da compreensão do conhecimento para o ensino, com base em pesquisas em Educação Científica.

Para finalizar, destaca-se o importante papel desempenhado pelas tecnologias nesta pesquisa. A praticidade da elaboração, coleta e análise de dados dos questionários via plataforma do SurveyMonkey. Os benefícios e vantagens do uso do software webQDA, que auxiliou na definição de novas categorias e permitiu o cruzamento de dados que manualmente não seria possível.

\section{Referências}

Altet, M. (2001). As competências do professor profissional: entre conhecimentos, esquemas de ação e adaptação, saber analisar. In: L. Paquay, P. Perrenoud, M. Altet, \& E. Charlier (Org.). Formando professores profissionais: Quais estratégias? Quais competências? (pp. 23-36). Porto Alegre: Artmed.

Bardin, L. (2011). Análise de Conteúdo. (2. reimp. da 1. ed.). São Paulo: Edições 70.

Carvalho, A. M. P., \& Gil-Pérez, D. (2011). Formação de professores de Ciências: tendências e inovações. (10 ed). São Paulo: Cortez.

Carvalho, A. M. P., \& Gil Pérez, D. (2014). O saber e o saber fazer do professor. In: A. D. Castro, A. M. P. Carvalho (Org.). Ensinar a ensinar: didática para a escola fundamental e média. (pp. 107-124). São Paulo: Cengage Learning.

Clebsch, A. B. (2018). Construção dos saberes docentes na formação do licenciando em Física. Tese de Doutorado, Universidade Federal de Santa Catarina, Florianópolis, $\mathrm{SC}$, Brasil. 
Clebsch, A. B., \& Alves Filho, J. de P. (2018). Estudo da construção do Conhecimento Pedagógico de Física com apoio do webQDA. In: Atas CIAIQ 2018 - Investigação Qualitativa na Educação (Vol. 1). Aveiro: Ludomedia, pp. 560-569.

Costa, A. P., \& Reis, L. P. (2017). Vantagens e desvantagens do uso de software na análise de dados qualitativos. RISTI - Revista Ibérica de Sistemas e Tecnologias de Informação, (23). DOI: 10.17013/risti.23.0

Costa, A. P., Linhares, R. \& Neri de Souza, F. (2012). Possibilidades de Análise Qualitativa no webQDA e Colaboração entre Pesquisadores em Educação em Comunicação. In Atas Simpósio de Educação e comunicação (Vol. 3). Aracajú: Universidade Tiradentes, pp. 276-286.

Fonseca, C. V., \& Santos, F. M. T. (2015). O Curso de Licenciatura em Química da UFRGS: Estudo da Estrutura Curricular e de Aspectos Constitutivos da Formação Docente. ALEXANDRIA, Florianópolis, 8(3), 81-111.

Freitas, F., Souza, F. N. de, Costa, A. P., \& Mendes, S. (2016). O Manual de Utilizador de um Software de Análise Qualitativa: as perceções dos utilizadores do webQDA. RISTI - Revista Ibérica de Sistemas e Tecnologias de Informação, (19), 107-117. DOI: 10.17013/risti.19.107-117.

Melo, L., Cañada, F. \& Díaz, M. (2017). Formación continua del profesorado de Física através del conocimiento didáctico del contenido sobre el campo eléctrico en Bachillerato: un caso de estudio. Caderno Brasileiro de Ensino de Física, 34(1), 131-151.

Montenegro, V. L., S. \& Fernandez, C. (2015). Processo reflexivo e desenvolvimento do conhecimento Pedagógico do Conteúdo numa intervenção formativa com professores de Química. Revista Ensaio, 17(1), 251-275.

Neto, A. L. G. C., \& Amaral, E. M. R. (2013). Abordagens sobre a prática docente em pesquisas em ensino de Ciências no período de 2002 a 2012. In: Atas Encontro Nacional de Pesquisa em Educação em Ciências. Águas de Lindóia. São Paulo.

Park, S., \& Oliver, S. (2008). Revisiting the Conceptualisation of Pedagogical Content Knowledge (PCK): PCK as a Conceptual Tool to Understand Teachers as Professionals. Research in Science Educacion, 38 (3), 261-284.

Porlán Ariza, R., Rivero García, A. (1998). El Conocimiento de los profesores: una propuesta formativa en el área de ciencias. Sevilha, Espanha: Díada Editora.

Resolução n. 1, de 18 de fevereiro de 2002. (2002). Institui Diretrizes Curriculares Nacionais para a formação de professores da Educação Básica, em nível superior, curso de Licenciatura, de graduação plena. Recuperado de: http://portal.mec.gov.br/seesp/arquivos/pdf/res1_2.pdf

Resolução n. 2, de 19 de fevereiro de 2002. (2002). Institui a duração e a carga horária dos cursos de Licenciatura, de graduação plena, de formação de professores da Educação Básica em nível superior. Recuperado de http://portal.mec.gov.br/cne/arquivos/pdf/CP022002.pdf 
Resolução n. 2, de 1 de julho de 2015. (2015). Define as Diretrizes Curriculares Nacionais para a formação inicial em nível superior e para a formação continuada. Recuperado de: http://portal.mec.gov.br/docman/agosto-2017-pdf/70431-res-cne-cp-00203072015-pdf/file

Santos, G. R., \& Lisovski, L. A. (2011). Prática como Componente Curricular: análise de trabalhos apresentados no período de 2002 a 2010. In: Atas Encontro Nacional de Pesquisa em Ensino de Ciências. Campinas: UNICAMP.

Shulman, L. S. (1987). Knowlege and Teaching: Foundations of the new Reform. Harvard Educacional Review, 57(1), 1-22.

Shulman, L. S. (1986) Those who Understand: Knowledge Growth in Teaching. Educacional Researcher, 15(2), 4-14.

\section{Agradecimento}

À Coordenação de Aperfeiçoamento de Pessoal de Nível Superior (CAPES) pelas bolsas nos últimos meses de doutorado, concedidas via programa PRODOUTORAL do Instituto Federal Catarinense (IFC). 